\title{
A CGI approach to \\ valuable historical technical heritage archival - for increasing awareness of industrial technologies and for use in technical education -
}

\author{
Tomoaki SATO* \\ *Kanagawa Institute of Technology \\ 1030 Shimo-Ogino, Atsugi-shi, Kanagawa 243-0292, Japan \\ E-mail: satotomo@gen.kanagawa-it.ac.jp
}

Received: 16 February 2017; Revised: 5 April 2018; Accepted: 10 April 2018

\begin{abstract}
In this research, our goal is to create multimedia content for selected machinery, aiming to communicate to future generations the operating behaviors of these machines valued as items of technological heritage. Thus far, three devices registered as Japanese heritage machinery have been modeled in 3D-CAD form, digitally assembled as a virtual reproduction and then animated to complete the CGI content. The selected machinery is listed below. 1) The hauling machinery at the Kosuge Ship Repair Dock at the Mitsui Historical Shipyards Museum was selected as the preeminent piece of Japanese heritage machinery by the Japan Society of Mechanical Engineers; 2) the third-ranked piece of heritage machinery, Kaheji Ito's forged-iron treadle lathe (Meiji 8/1875) is preserved at the Meiji Village open-air museum in Aichi prefecture; 3) the fourth-ranked piece of heritage machinery is the land steam turbine (Meiji 41/1908, Mitsubishi Joint Stock Corporation). These completed projects have all been donated to their respective museums to provide enlightenment and guidance to visitors.
\end{abstract}

Keywords : Technical heritage, Digital archive, CGI, Animation, 3DCG, Technology education

\section{Introduction}

Digitizing historic cultural assets and creating videos to demonstrate the form and function of these assets is seen by today's society as a highly effective means of raising awareness of cultural and technological traditions.

In 2011, UNESCO launched the "World Heritage Memory Net," (UNESCO, 2018) an on-demand environment in which world heritage items can be viewed. This website makes 911 world heritage artifacts from 151 countries available in digital form, to a worldwide audience. The site contains photos, videos, and audio clips. There are countless Japanese cultural assets, including digital ones, such as the restored Great Buddhas by Oishi et al. (2005). Animated CGI (Computer Generated Imagery) models created using 3D-CAD software while at engineering school were used to advance the author's understanding of the structures of various machines (Sato et al., 2007, 2008). Among those, believing it to have historic value, the author used 3D-CAD software to animate a CGI model of a historical air-cooled horizontally opposed aircraft engine produced during the World War II, (Lycoming O-290 Type A) (Sato, 2012). If these technical CGI contents are archived and opened to the public, such as with the World Heritage initiative mentioned above, it will be possible to bring greater awareness of industrial technologies to society. Moreover, this CGI content can be an effective teaching resource for both middle school technology departments and high school engineering departments. Assessing older machines, reproducing their state of operation, and demonstrating them to the public is a highly effective means of raising awareness of technological traditions. As such, the creation of CGI digital reproductions of historically and technologically valuable machines is sure to promote technological tradition in places of learning and teaching. 


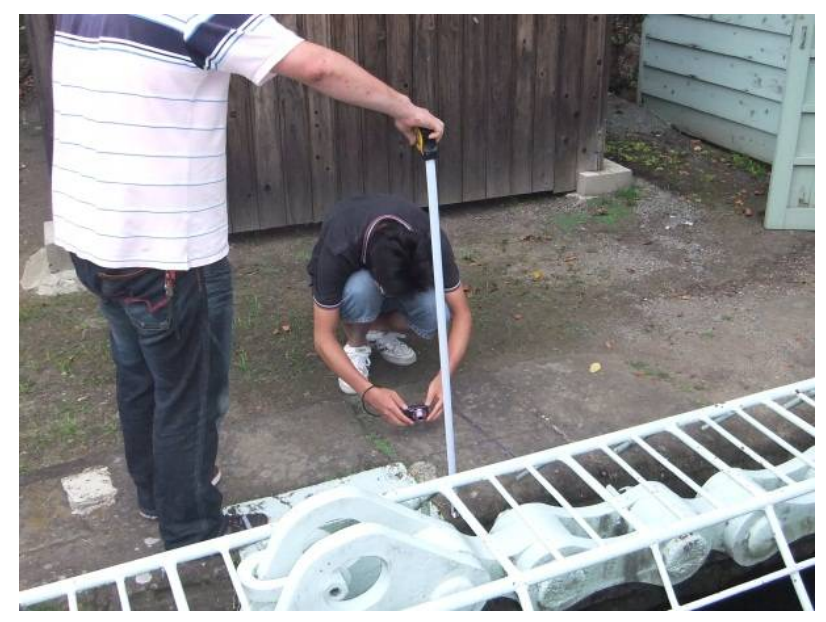

Fig. 1 We measured the dimensions of the machine like this picture.

This figure shows the measurement scenery of the winch dimension.

In other studies, there are several reports on 3D digital modeling of historically and technologically valuable machine tools by Nippon Institute of Technology Museum of Industrial Technology (Tanji and Matsuno, 2015, 2016), but there are few studies on this theme yet. Therefore, we focused on the Mechanical Engineering Heritages certified by the Japan Society of Mechanical Engineers and tried to create those CGI contents.

Currently, CGI animated contents for the hauling equipment at the Mitsui Historical Shipyards Museum in Nagasaki prefecture have been created, selected as the most important item of Japanese industrial heritage by the Japan Society of Mechanical Engineers in 2007. Kaheji Ito's forged-iron treadle lathe from 1875 (Meiji 8) is also represented, preserved at the Meiji Village open-air museum in Aichi prefecture, selected as the third most important piece of Japanese technological heritage in 2007. Additionally, the Mitsubishi land steam turbine from 1908 (Meiji 41) is presented, ranked as the fourth most valuable item of industrial heritage (Sato, 2013, 2014, 2015).

This paper offers further details about these items and describes their digital reproductions and the methods of their creation.

\section{Content Development Techniques and Processes}

\subsection{Measurement of Dimensions}

Given the age of the heritage technologies included in this initiative, there are often no remaining documents or blueprints. Therefore, prior to creating CGI reproductions, it was necessary to physically measure the dimensions of the machinery. These measurements were performed directly using calipers, micrometers, or tape measures, but often it was not possible to touch the machinery directly. In these cases, a photograph was taken with a scale measure placed near the equipment, and the dimensions of the machinery were later measured via comparison, by proportional distribution, using the photograph. Figure 1 shows the measurement of selected machinery's dimensions.

\subsection{CGI Production Environment and Development}

Creo Elements 5.0, a 3D-CAD software package produced by PTC, was used for modeling the digitized data. This software can leverage parametric feature-based modeling to perform 3D solid modeling. Because the exterior shape of a solid is stored as a dimensional value alongside data related to other solids, dimensions can be easily changed by adjusting their sizes and relationships. Entering 3D measurement data for each equipment component, the software creates model data for each section. Animations are created by applying animation commands, included in Cero Elements 5.0, to the model data.

\section{Technological Heritage Recreated in CGI}

Some of the heritage technologies and their CGI recreations, thus far included in this initiative, are described below.

\subsection{Shipping Winch at the Kosuge Shipyard}

\subsubsection{Overview}




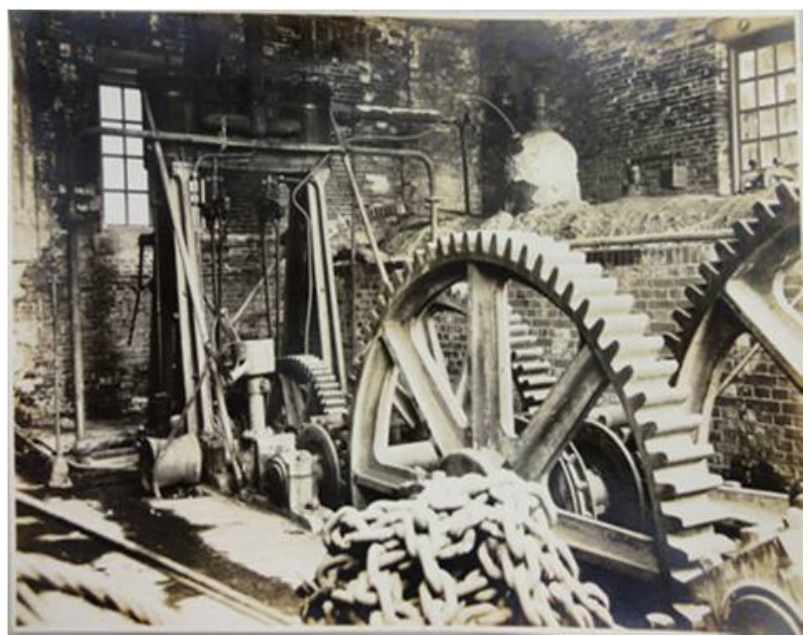

Fig. 2 This is the old picture of the overview of original shipping winch.

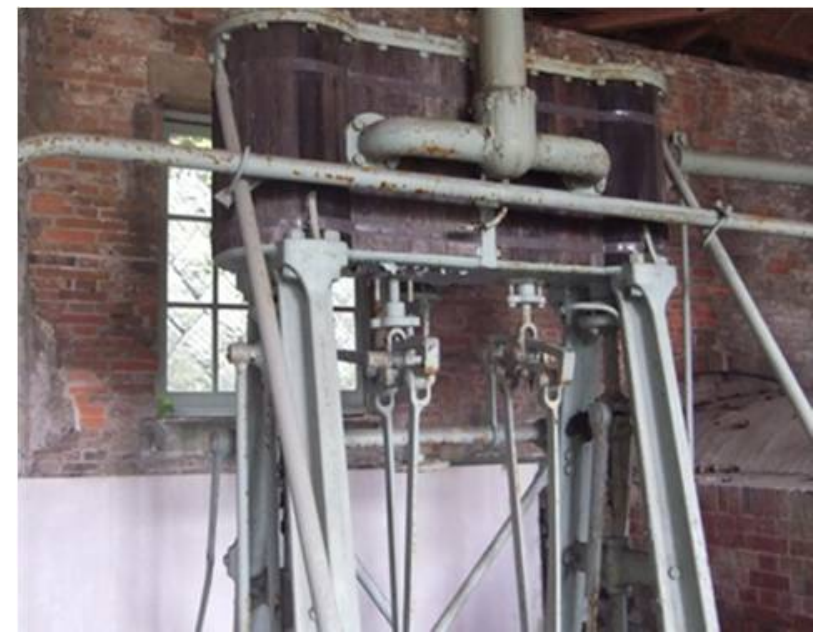

Fig.3 The steam-engine's piston section, as it stands today.

The first heritage technology to be included in this initiative is the shipping winch at the Kosuge ship repair dock, now part of the Mitsui Historical Shipyards Museum in Nagasaki prefecture. It was selected as the preeminent piece of Japanese heritage machinery in 2007 by the Japan Society of Mechanical Engineers. Constructed at the end of the Tokugawa period, this shipping winch was part of Japan's first modern shipbuilding facility. In 1867, the Satsuma clan, seeking to repair a steam ship purchased abroad, entered a joint investment project commencing that same year with the merchant trader, T. B. Glover. The project was completed in 1868. By using a slipway, a dog ratchet, and a winch, it was possible to lift ships weighing 1,000 tons. The steam winch used gears with a boiler, imported from England, and a rigid 2-cyl, $25 \mathrm{HP}$ steam engine to lift ships. The winch hut that houses the equipment is thought to be the first brick-built construction in Japan. In 1969, the waterfront, including the winch hut, berths, and revetments, having a combined area of $8,400 \mathrm{~m}^{2}$, were designated as a site of Important cultural property. Moreover, in 2007, it was selected as the most important piece of heritage machinery in Japan by the Japan Association of Mechanical Engineers. In 2015, following a national recommendation, it was designated a UNESCO World Heritage Site as part of "Sits of Japan's Meiji Industrial Revolution". Figure 2 shows the engine body in operation, whereas Fig. 3 shows the piston section as it stands today.

\subsubsection{CGI Content}

The CGI animation of the sections of the steam engine are shown in Fig. 4, Fig.5, and Fig.6. Figure 4 shows the reduction gear train that conveys force from the steam engine to the winch apparatus. Because the steam engine's cylinders, pistons, and valves cannot be examined directly, their structure is inferred from external measurements. 


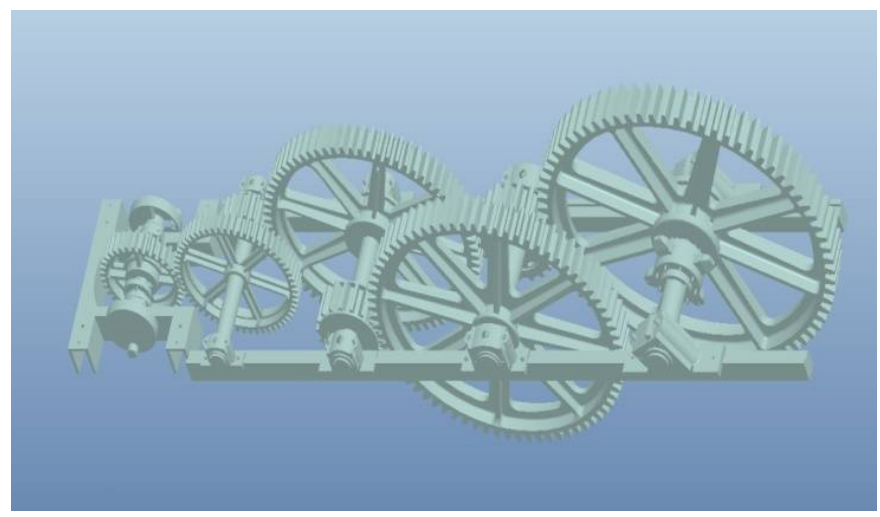

Fig. 4 The CGI-Generated of the reduction gear train that conveys force from the steam engine to the winch apparatus.

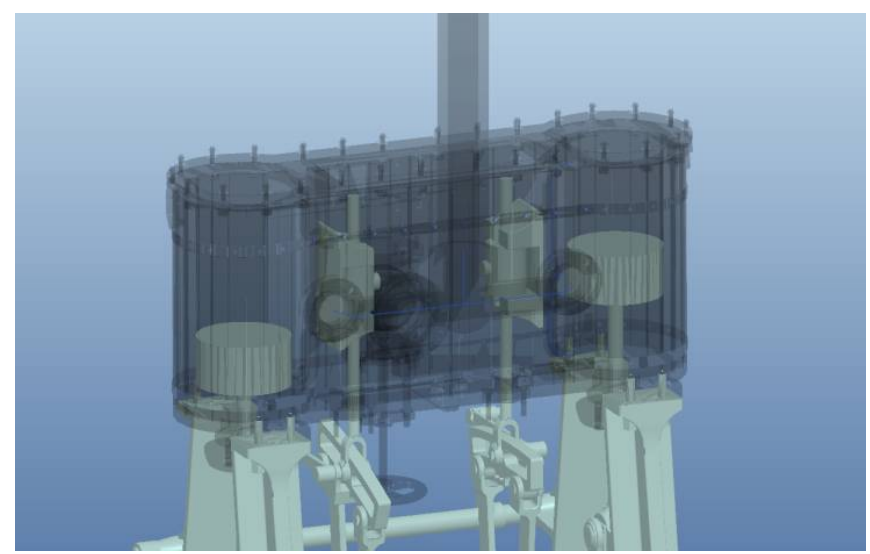

Fig. 5 The CGI-Generated of the cylinder valve.

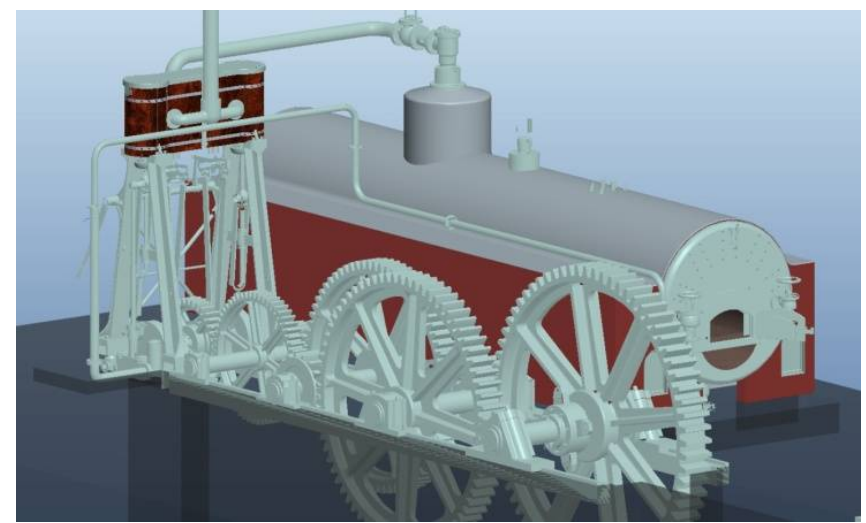

Fig. 6 The CGI-Generated of the steam engine exterior view.

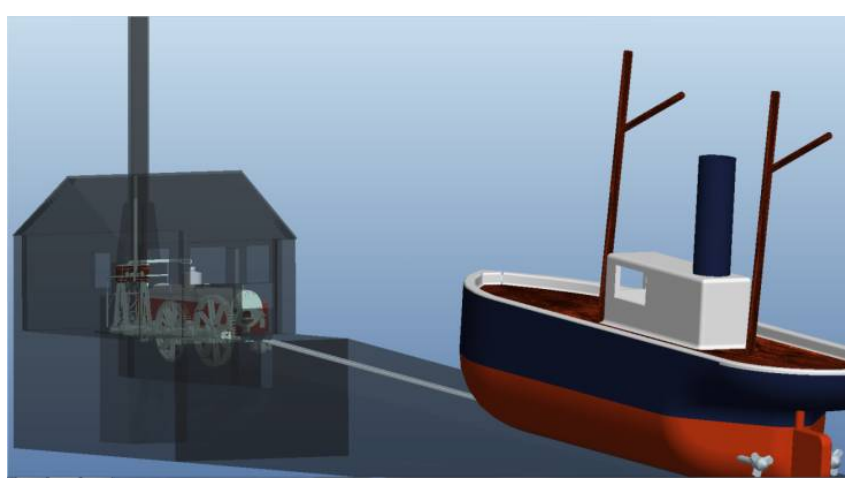

Fig. 7 The CGI-Generated of the exterior view of the winch equipment. 


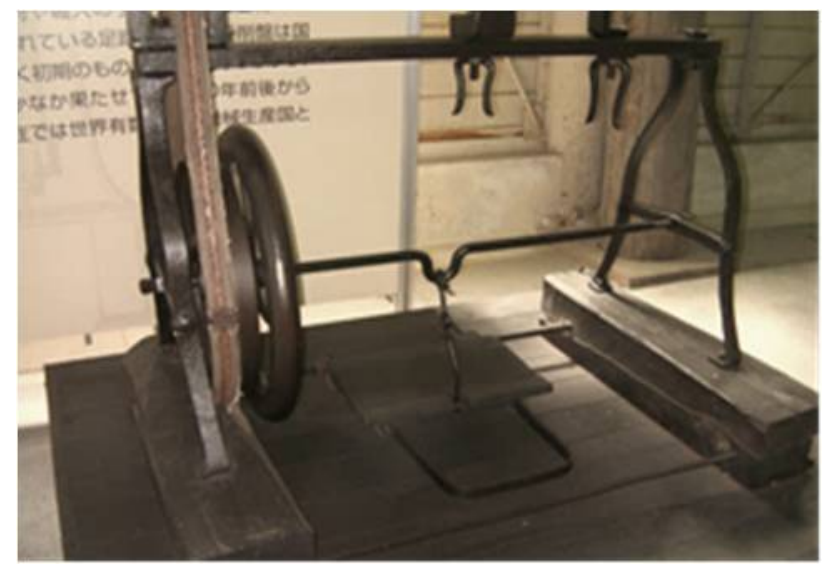

Fig. 8 The Treadle Lathe as it stands today.

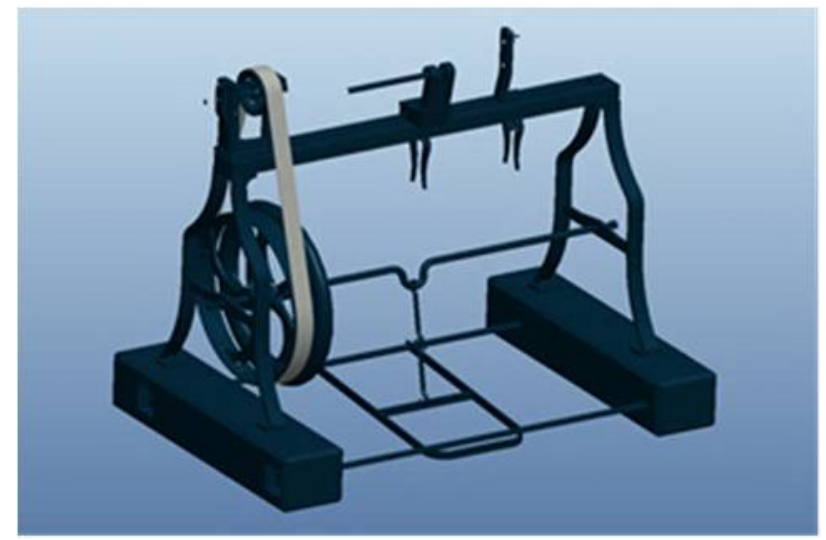

Fig. 9 The CGI-Generated of the Treadle Lathe.

The bore diameter was $280 \mathrm{~mm}$. For the valve system, a Stephenson valve was used, having been the most widelyused format at the time. For the interior section, piping was run to allow steam to flow from the steam chamber to the top and bottom of the cylinders and to discharge steam outside. Fig. 5 offers a clear model of the steam chamber and cylinders, making it easy to see the internal construction. The boiler is installed at the rear. Because disassembly is impossible, there is no way to examine the boiler's internal structure in detail. However, based on observations through the grate of the firebox, it is assumed to be a single-flue Cornish boiler. Fig. 7 was created to show the machinery in its entirety, including the ship winch. Because Fig. 4 through Fig. 7 were all constructed using the same data viewed from different positions and angles, it is possible to zoom up and down, as well as to turn the objects while interacting with them.

\subsection{Treadle Lathe}

\subsubsection{Overview}

This treadle lathe is registered as the third-ranking piece of Japanese heritage machinery (Fig. 8). This treadle lathe, produced in c.1875, is regarded as the first fully-forged iron lathe to be produced in Japan. Kaheji Ito trained at Japan's first private machinery manufacturing plant, the Tanaka factory (now Toshiba), and produced the treadle lathe after returning home to Yamagata. Kaheji Ito's forged iron treadle lathe was donated to the Tokyo Institute of Technology in 1932, and has since been used as a reference for future machine tool development, and is now on display at the Meiji Village open-air museum's Machinery Exhibit in Inuyama, Aichi prefecture.

\subsubsection{CGI Content}

The animation of the treadle lathe is based on the mechanics of the rotation mechanism. However, the static section was designed and positioned first. Next, each part of the rotating section was assembled with the axes aligned. Then, they were placed on the base section, and the rotation was animated (Fig. 9).

\subsection{First domestically produced land steam turbine 3.3.1 Overview}




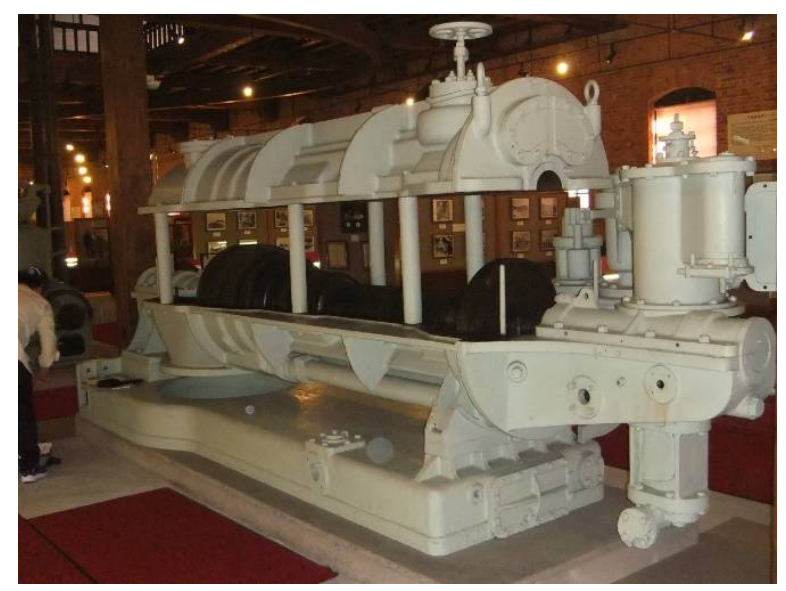

Fig. 10 Steam Engine Exterior as it stands today.

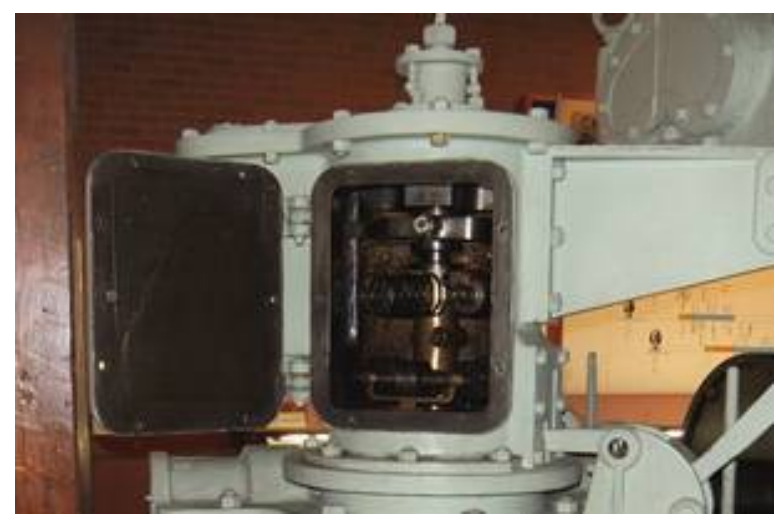

Fig. 11 Speed Governor Section as it stands today.

The land steam turbine, the first to be domestically-produced, was built in October 1908 (Meiji 41) by the Mitsubishi Joint Stock Company (predecessor of Mitsubishi Heavy Industries) at the Nagasaki Shipyards. In 1904 (Meiji 37) Mitsubishi Joint Stock Company, in technical cooperation with England' s Parsons Company, completed a $500 \mathrm{~kW}$ Parsons steam turbine and a $625 \mathrm{~kW}$ generator and began private power generation on-site. This land steam turbine was operated at 2,400 rpm at $1.03 \mathrm{MPa}$, using steam at $186^{\circ} \mathrm{C}$. Although the steam pressure was as low as the current geothermal turbine level, it had a total of 84 stator blades. The 23 blades of the high-pressure section were made from copper, whereas the 61 blades of the medium and low-pressure sections were made of brass. The machine operated in its factory power supplying role until 1920. Today, its turbine rotors, blades, drive housing and governors are preserved, on display, at the Mitsubishi Heavy Industries Nagasaki Shipbuilding Historical Museum. In 2007, the land steam turbine was selected as the fourth-ranked piece of heritage machinery by the Japan Society of Mechanical Engineers. Figure 10 shows the body of the engine, whereas Fig. 11 shows the governor section.

\subsubsection{CGI Content}

The CGI-content was first modeled in the same fashion as the above two cases, using the Creo Elements CAD software, after which, the 3D modeling data was imported to and animated using a separate animation package (i.e., Autodesk's Maya software (Fig. 12)). Moreover, captions and sounds were subsequently added to finish the animation using Microsoft Windows Movie Maker. Figure 13 shows the cross-section of the governor housing using modeling data assembled using Maya. Figure 14 shows the external view of the entire turbine body. The 3D representation of the turbine's rotation is set to a much slower rotation speed than the original $100 \mathrm{rpm}$ to clearly display the mechanics. The animation is observed through a virtual camera moving through the modelled environment. Figure 15 shows a cross-section view of the animation of the turbine's operation. 


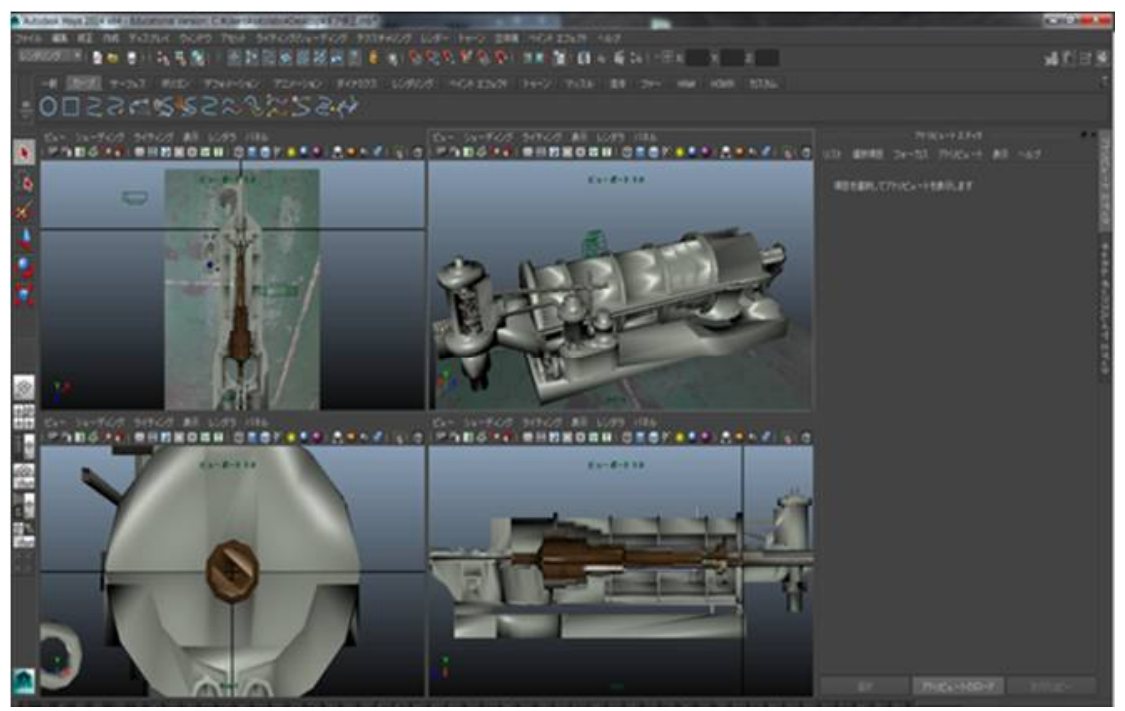

Fig. 12 The 3D modeling data was imported to and animated using a software of Autodesk's Maya which is the design editing interface.

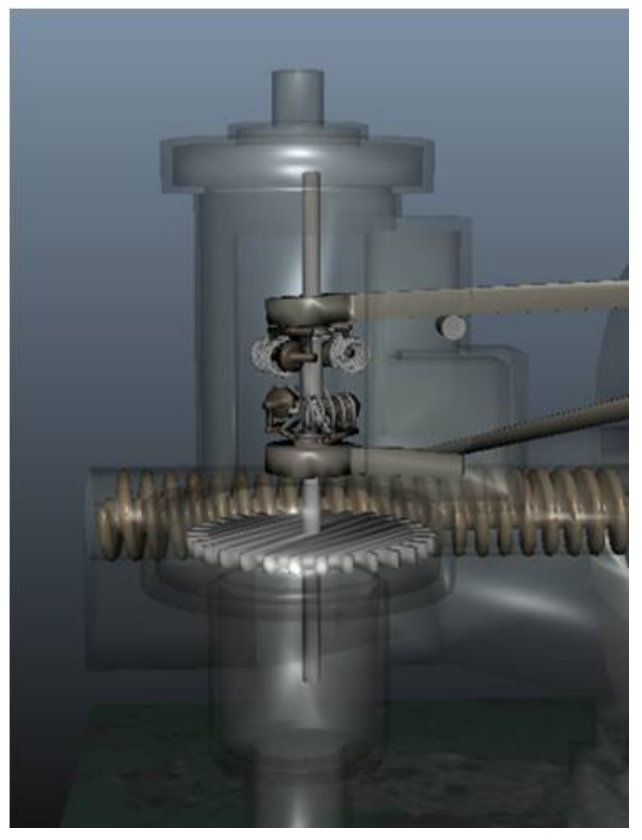

Fig. 13 The CGI-Generated of the Governor Section.

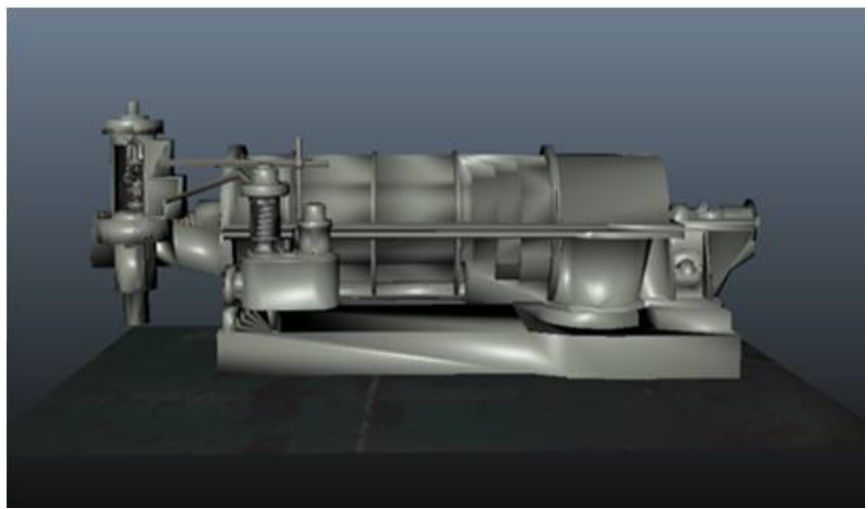

Fig. 14 The CGI-Generated of the Turbine Engine body.

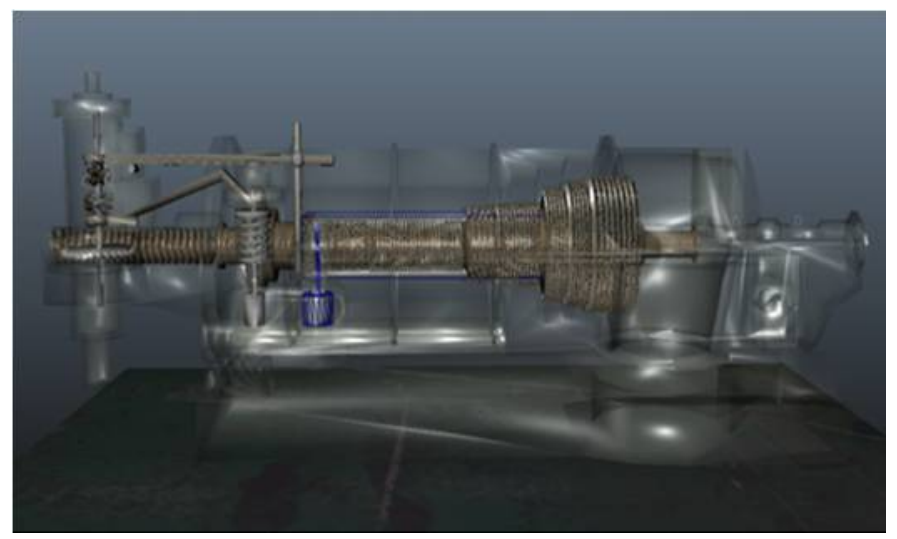

Fig. 15 The CGI-Generated of the Interior Cross Section. 


\section{Conclusion}

With this initiative, our goal is to create multimedia content for selected machinery, aiming to communicate to future generations the operating behaviors of these machines valued as items of technological heritage. Thus far, three devices registered as Japanese heritage machinery have been modeled in 3D-CAD form, digitally assembled as a virtual reproduction and then animated to complete the CGI content. The selected machinery is listed below.

1) The hauling machinery at the Kosuge Ship Repair Dock at the Mitsui Historical Shipyards Museum was selected as the preeminent piece of Japanese heritage machinery by the Japan Society of Mechanical Engineers; 2) the thirdranked piece of heritage machinery, Kaheji Ito's forged-iron treadle lathe (Meiji 8/1875) is preserved at the Meiji Village open-air museum in Aichi prefecture; and 3) the fourth-ranked piece of heritage machinery is the land steam turbine (Meiji 41/1908, Mitsubishi Joint Stock Corporation). These completed projects have all been donated to their respective museums to provide enlightenment and guidance to visitors.

The CGI contents of the Kosuge Ship Repair Dock Winch machinery were demonstrated at a presentation made during UNESCO's consideration of the site for World Heritage status, therein contributing to the site's World Heritage certification.

\section{Acknowledgements}

This endeavor is undertaken as part of graduate study for the students of the Kanagawa Institute of Technology, the institution to which this author belongs. I express my deepest appreciation to Mr. Ryhohei Sato, Mr. Tatsuhiro Ueno, Mr. Takaharu Ishikawa, Mr. Takahiro Morya, Mr. Masakazu Okada, and Mr. Masahiro Hirano, who were students of the Mechanical Engineer Department of the Kanagawa Institute of Technology at the time, who aided in both gathering the measurements of these historical machines as well as their digital recreations.

\section{References}

Ohishi, T., Masuda, T,. Kurazume, R., Ikeuchi, K., So, K., Digital Restoration of The Original Great Buddha and Main Hall of Todaiji Temple, Transactions of the Virtual Reality Society of Japan, Vol.10, No.3 (2005), pp.429-436 (in Japanese).

Sato, T., Nagaoka, K., Oguchi, K., Research on Effective Utilization of CGI Content to Promote Understanding of the Operating Principles of the Internal Combustion Engine - The outcomes of e-learning content and animations to explain principles on learning -, Transactions of the JSME Ser. C 73.725 (2007), pp.35-43 (in Japanese).

Sato, T., Development of Teaching Materials Using Stereoscopic 3D CGI Animation, Journal of JSEE Vol.56, No.6 (2008), pp.102-107 (in Japanese).

Sato, T., Creation of a 3D CGI Model of a Horizontally Opposed 4 Cylinder Aircraft Engine, Mechanical Engineering Congress Japan 2012 (JSME: MECJ-12) (2012), No. S202016 (in Japanese).

Sato, T., Sato, R., Ueno, T., Creating Multimedia Contents of the Kosuge Winch Equipment, Annual meeting of Technical and Social Division of JSME 2013 (2013), No. 130 (in Japanese).

Sato, T., CG Contents of the Treadle Lathe, Mechanical Engineering Congress Japan 2014 (JSME: MECJ-14) (2014), No. S2030205 (in Japanese).

Sato, T., CG Content of the Land Steam Turbine, Annual meeting of Technical and Social Division of JSME 2015 (2015), No. 212 (in Japanese).

Tanji, A., Matsuno, K., Research of machine technology history using a 3D-models of the machine tool produced in Showa era, Mechanical Engineering Congress Japan 2015 (JSME: MECJ-15) (2015), No. S2010106 (in Japanese).

Tanji, A., Matsuno, K., Research of the railway vehicle fabrication method for which a 3D-models of the machine tool of the Showa era, Mechanical Engineering Congress Japan 2016 (JSME: MECJ-16) (2016), No. G2000102 (in Japanese).

UNESCO, World Heritage Memory Net (WHMNet) Archive, available from $<$ http://whmnet.org/>, (accessed on 2 February, 2018). 